\title{
La caricatura goyesca en el Woyzeck de Büchner
}

\author{
JoRGE SECA \\ Universidad Autónoma \\ de Barcelona UAB
}

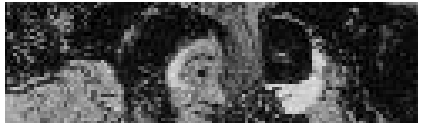

«Nadie se conoce» (Caprichos, nº 6, Francisco DE GoYA)

«Todo estaba muerto» (Woyzeck, Escena 21)

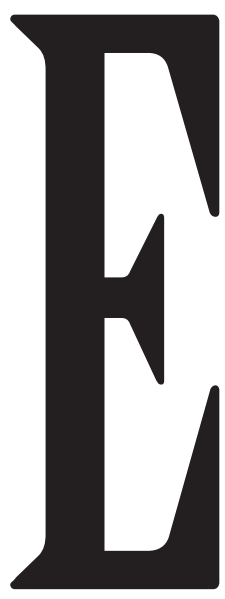

n Woyzeck se tocan la desmesura y la realidad; son lo mismo. En otros campos de interpretación diríamos que la tragedia se alía a la comedia grotesca, o que la nueva clase ascendente, la burguesía, ha de distinguirse de la clase aristócrata mediante la exacerbación del puritanismo en las relaciones humanas frente a la relajación «natural» de la aristocracia. Sin embargo, ese tipo de clasificaciones no nos conduce a casi nada, y esta breve obra maestra expresa muchísimo más. El escenario, como siempre, agrupa a unos seres determinados, hombres y mujeres, con unos conflictos específicamente humanos pero vueltos a lo animal, a lo bestial, hasta el punto de que es fácil advertir en los personajes ciertos atisbos de plumas, picos, rabos, cuernos e incluso gigantescos colmillos de elefante que a modo de jeringas encrespan a sus semejantes hasta llevarlos a situaciones límite, entre la espada y una pared que es techo y suelo, un estrecho espacio, suficiente para ahogar de asfixia al más audaz anfibio. Una cadena que dirige sus eslabones hacia otros espacios, a modo de tentáculos, nos hace sospechar que tal vez no se trata de un conflicto local, y que así es el ser humano universal. ¡Pero no vaya uno a pensar que eso sea así en efecto, no! Una sospecha de ese calibre es demasiado brutal, y gracias a nuestra sabia moral nos decimos que en el reconocimiento del error está la sabiduría. Sí, pero ¿qué error? El búho y la serpiente viven en una misma persona y, a veces, no pueden separarse sin riesgo de matar al cisne. Por eso el búho ulula desde el salvaje vientre de la serpiente, o como dice María: «Todo es lo mismo».

A Büchner el canto de cisne le debió parecer falso o acaso asumió completamente su destino de hombre de denuncia, incapaz de permanecer impasible y de soportar los abusos del ser humano sobre los seres humanos. Demasiado joven y ya herido de contaminadas enfermedades humanas. Era incapaz de elaborar ya un arte como el de Goethe en Ifigenia, pero era artista al fin y al cabo en su compromiso social.

Un hombre y una mujer se buscan sin saberlo. Deberían estar más unidos que nunca para ahuyentar la marca de culpables que los demás les han colgado; pero están separados, solos. El hombre, Woyzeck, está preocupado por descifrar un enigma que se le anuncia en un campo de setas; enigma que cuanto más

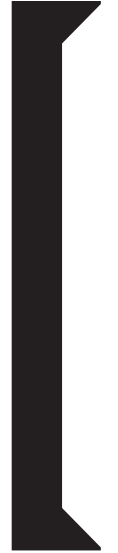

El coro de los personajes querodean

a Woyzeck se aplica afanosamente

por darles la luz necesaria,

yademás, exactamentela que deben tener. se esfuerza en desentrañar más lo acerca a su destino de criminal. Ese destino ya está escrito con su hora exacta en el mismo campo de setas: «Ahí rueda la cabeza por la noche» (escena 1). La mujer, María, preocupada por las joyas, por el oro y por todas las galas de que carece en su condición de mujer pobre. Su drama consiste en que le falta un hombre para su sed de mujer. Víctima consciente de su destino, desafía a éste con las imágenes de un cuchillo que la ha de matar, pero siente miedo cuando ese cuchillo se aproxima inevitable ya a su cuello.

¿Una simple tragedia de celos? No; el conflicto ahonda en el conocido sentimiento de impotencia ante un tiempo y unos acontecimientos que se adelantan a nuestra propia decisión; un sentimiento de títere, de insignificancia, de lucha inútil y de condenación eterna. Éste es en definitiva el tema principal de la obra; un tema sencillo, si se quiere incluso muy elaborado ya, pero siempre inagotable y nuevo. Con Büchner este tema adquiere un personal tratamiento: a) Los personajes ya sólo son caricaturas de seres humanos, son exactamente animales; b) aunque hay numerosas alusiones a lo sobrenatural e intentos de ennoblecer el tema del destino a la manera de las tragedias clásicas (sobre todo por parte de Woyzeck) lo cierto es que la realidad es apabullante y ahoga toda inclinación artísticamente noble. En esta obra parece que el personaje estuviera buscando su propio escenario ideal para desenvolverse, pero cuando echa una mirada a su entorno se da cuenta de que la fatalidad de su destino tiene por fuerza que asemejarse a la miseria que le circunda; y no se le permite ninguna grandilocuencia que vaya más allá de la ventosidad, ni ninguna imagen que no delate los agujeros en la ropa ni 


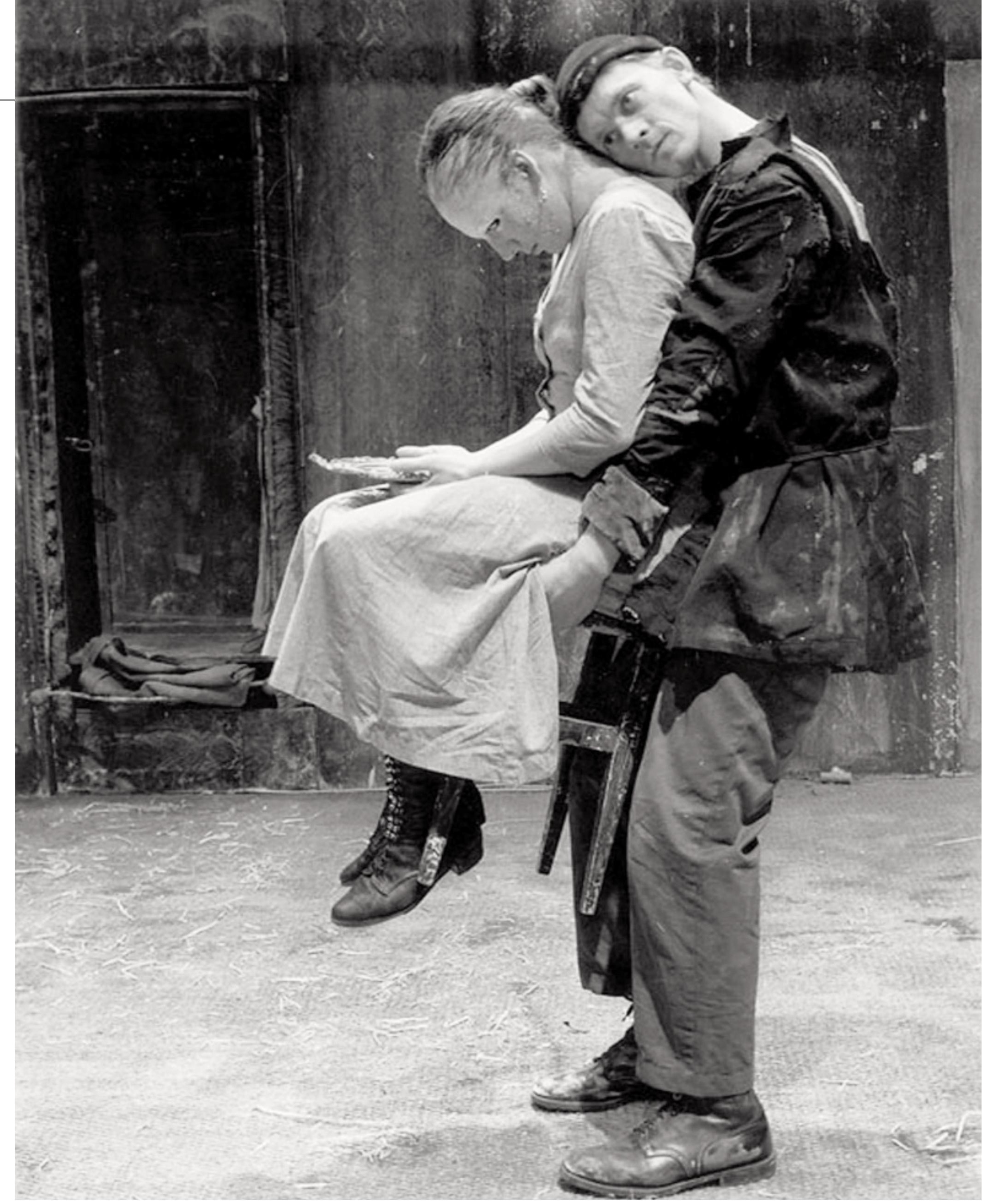


los tristes guisantes de la comida. Aquí los personajes comen, beben, joden y se orinan. Los escasos y temerarios intentos por ocultar estas manifestaciones son inútiles. El coro de los personajes que rodean a Woyzeck se aplica afanosamente por darles la luz necesaria, y además, exactamente la que deben tener. Con estas características, ¿no tenía que huir necesariamente la poesía? Y esta huida, ¿no es la tragedia de la pérdida de la inocencia, la pérdida de la magia poética, el abandono de la flor azul? Pero dándoles la vuelta a estas cuestiones, ¿no cabe preguntarse si no era ésta precisamente la intención del autor, es decir, desechar lo que no pertenece al dominio de la realidad, desechar la apariencia (el arte) para hacer más visible la realidad? La posición del autor vista así parece tajante, pero ¿cómo hemos de llamarle: lúcido, disidente, genial, artista, cronista? No debería estar en el ánimo de ningún crítico el letrero fácil; y si es irremediable acudir a él debería utilizarse únicamente para constatar un cambio de orientación en las letras, un cambio que también es ostensible en Grillparzer, aunque a retazos, pues a éste le queda la alternativa y la esperanza de volver a trabajar en las tragedias de tipo mitológico. Büchner debió sentir también una incapacidad para abandonarse por completo al arte, una imposibilidad de volver a las formas clásicas. Para él la antigua estética no podía pervivir y no podía sostenerse en el recuerdo. Büchner no era ni hipócrita ni ciego. El resultado, la obra, es una parodia, una triste caricatura metida de lleno en la realidad.

Al pobre músico de Grillparzer le señalaban con el dedo y recibía las órdenes de su padre por medio de otros; él se había acostumbrado resignadamente. En cambio Woyzeck es víctima de leyes y oscuros mandamientos morales, de murmuraciones con un fondo real que no puede ni admitir ni soportar precisamente por esos abstractos conceptos de virtud y moral. Asesina con un mandato que le viene tanto del exterior como del interior, pero la verdadera fuerza expresiva para acometer su crimen está en las groseras imágenes revestidas de sociedad y de virtud que el capitán y el doctor le muestran.

El coro de las tragedias clásicas griegas vuelve también parodiado a la escena de Woyzeck. Antes describía el tema principal en el conflicto de destino entre María y Woyzeck. Pues bien, el resto de los personajes actúa a modo de coro de la tragedia que se cierne sobre ellos dos.

Como las pruebas que Pamino y Pamina en La flauta mágica deben realizar para purificar su amor y para ejercer su noble mandato sobre el resto de la humanidad que los aclama como príncipes, así Woyzeck recorre como por un túnel las normas que rigen a las demás personas, pero en vez de triunfar sobre el mal, sobre los poderes diabólicos, éstos acaban por poseerlo a él mismo; en parte porque no es un príncipe como Pamino sino «un pobre soldado», en parte porque su mujer es «una pobre mujer» que no es virgen ni virtuosa sino ramera (no lo es al principio de la obra sino al final, y cae en esta fatalidad porque «la sociedad virtuosa» considera ilícito el hijo fuera del matrimonio; la llaman ramera por esta razón; cuando consuma el hecho por el cual verdaderamente se le podría llamar así en esa sociedad, María ha asumido la culpabilidad de lo que la acusan; actúa como ramera porque para los demás ya lo es. También, igual que Woyzeck, ha sido arrastrada por la murmuración y los mandamien- tos de una sociedad que lo es todo menos moral, aunque se jacta de poseer la clave de la moralidad).

El dilema está en que la virtud buscada por la razón ingenua de Woyzeck: «El Señor dijo: dejad que los niños se acerquen a mí» (escnena 2) no corresponde a lo que el capitán y el doctor llaman así. La locura de Woyzeck, su sed criminal de sangre, proviene de la imposibilidad de separar clara y matizadamente las esferas del bien y del mal, de no saber de qué lado inclinarse, si del lado de la sociedad con su peculiar código del bien (que es el mal) o si del lado de lo que le dicta su razón (que es el bien propiamente dicho por mandato bíblico-divino, pero que es el mal para los otros puesto que está en pecado). Este desajuste le desquicia, le imposibilita una decisión y aunque fuera un titán y la tomara no serviría pues fluye más poderosa aún que su determinación el destino de matar y morir.

Todo es anunciación. Todas las acciones están predichas y preparadas con antelación en el discurso de personajes-coro, seres que recuerdan el escenario de Shakespeare, seres que pertenecen

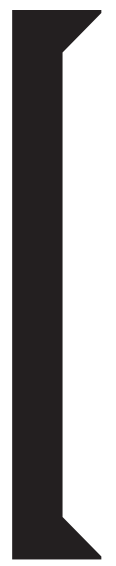

Hay una atracción irresistible de Woyzeck hacia la muerte. Toda la obra respira ese aliento fúnebre...

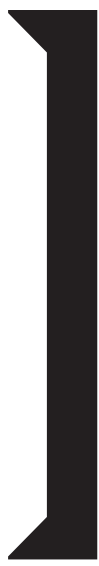

al mundo del teatro, comediantes, operarios, y que parodian también la comedia del mundo. En ese túnel que citaba antes y por el que pasa Woyzeck, todos los demás personajes le arrojan algo, una marca más que sedimenta en su interior y que se sumará a las otras hasta provocar el desbordamiento final. Woyzeck es un experimento de virtud, de «buena persona» para el capitán, y para el doctor es un ejemplar raro de la naturaleza al que hay que estudiar como a una rata de laboratorio para determinar la composición, pulso, alimentación, etc... (El personaje grotesco del doctor tuvo que ser por fuerza un espectro real e inenarrable que se le cruzó a Büchner en su vida de estudiante de Ciencias Naturales. Representa otra parodia. En la misma cortedad mental que el capitán, le habla a Woyzeck de lo que debe y no debe hacer; sus argumentos tienen un origen pseudocientífico. ¡Tiene justo el papel que le corresponde! Véasele también en la caricatura grotesca de Goya en el capricho: ¡Qué pico de oro! Caprichos, $\mathrm{n}^{\circ} 53$ )

Todos palpan el destino de Woyzeck menos él mismo (como en la Crónica de una muerte anunciada) pues está empeñado en descifrarlo. Pero todos lo palpan porque lo provocan, están puestos para que sea así. El capitán, a pesar de su estupidez, tiene una sentencia profética de una grosería ilimitada pero de una ex- 
presión rotunda: "Woyzeck corre como una navaja de afeitar abierta por el mundo; uno se corta en ella» (escena 9). Es una profecía más de entre las muchas que hay a lo largo de la obra. María también es profética y provoca el desenlace. Ella misma se sentencia: «¡No me toques, Franz! Preferiría tener clavado un cuchillo en el cuerpo a que me pusieras la mano encima» (escena 10). Ese cuchillo que planea por encima de Woyzeck, penetrándole hasta en el sueño, ¡ilo está pidiendo la propia víctima!! Hay una atracción irresistible de Woyzeck hacia la muerte. Toda la obra respira ese aliento fúnebre, unas veces revestido de lo

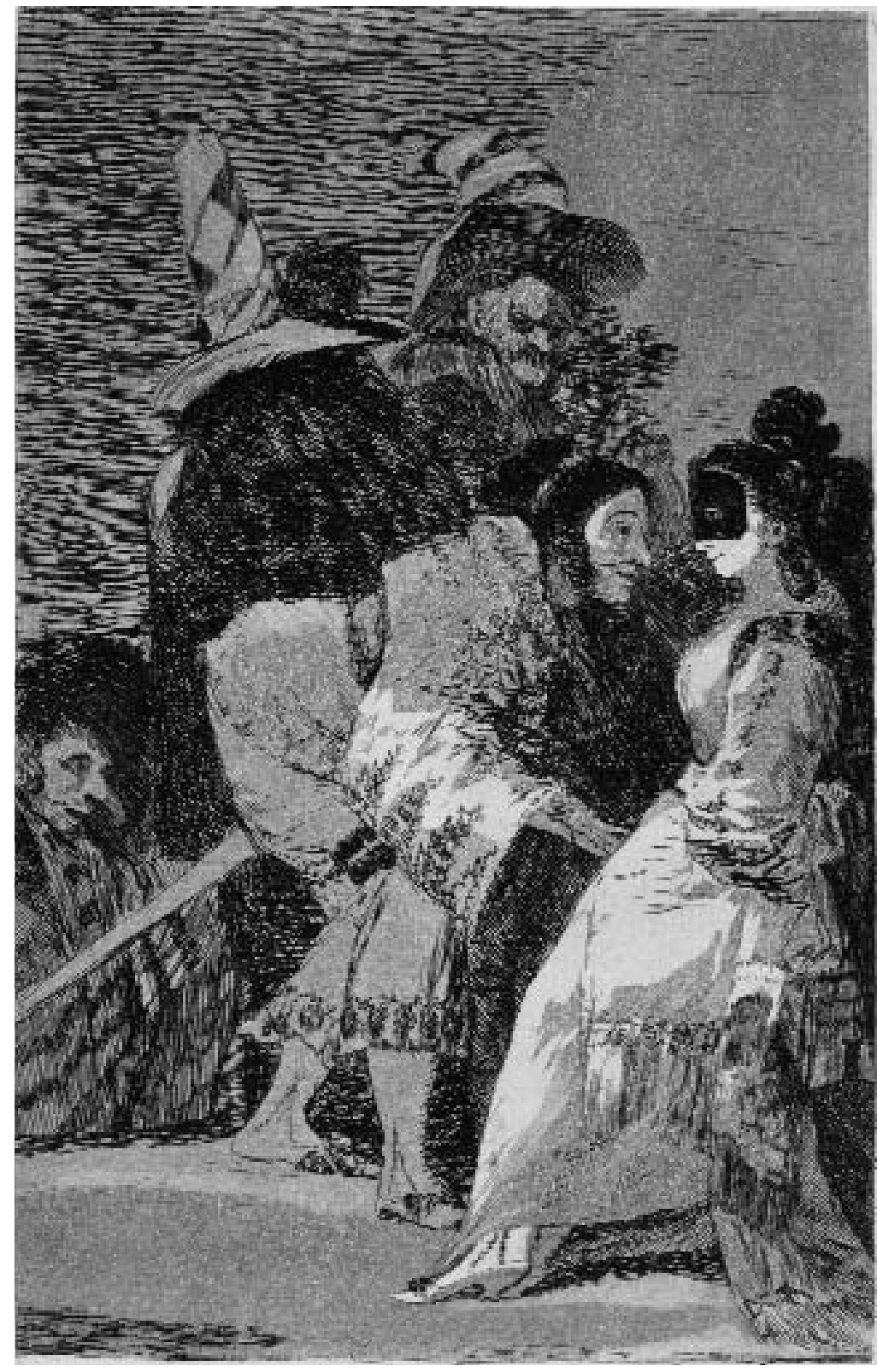

grotesco, otras de lo profundamente trágico. En la obra hay pocas sentencias, y una sola verdad de perogrullo: «En el mundo no hay nada duradero / todos tenemos que morir / bien lo sabemos» (escena 10). También ésta es una anunciación del final. Aparecen personajes como en un teatro mágico de la escena del mundo, y todos cantan a coro el destino de Woyzeck. Incluso él mismo. Para él, el «pecado» de María la convierte ya en cadáver cuando le dice a Andrés: « [...] ¡era una muchacha única!», adelantándose a su propio crimen.

Otro tema, unido al de la contradicción moral de la sociedad, lo conforma el de la contradicción religiosa. No hay límites justos entre lo que es el pecado y la virtud, Dios y el Diablo, amor y sexo. La cuestión fundamental es: la virtud, ¿es la palabra de Dios en la Biblia? Detrás de ella hay también una parodia. María se debate entre el poder diabólico y el poder divino. Su trayectoria en la obra es justamente la conversión por el arrepentimiento de María Magdalena en María Madre de Dios. María teme su propia falta porque se la considera un pecado y porque no hay una razón superior que una los extremos en apariencia irreconciliables, una síntesis superior y superadora como exigía el ideal de Schiller, por ejemplo. La Magdalena es el Diablo, la Madre de Dios representa el poder divino. María llora arrepentida: «Redentor, quisiera ungir tus pies» (escena

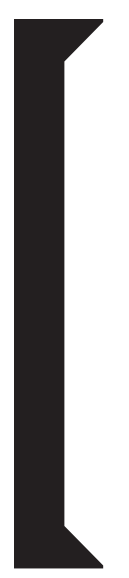

Mozart también debió pensar algo similar

cuando no supo qué hacer con el moro Monóstatos,

si condenarlo o simplemente separarlo

como el guisante agusanado de Grillparzer.

19). La virgen y la puta, esa dicotomía de nuestra sociedad y de nuestra cultura antigua y podrida, la dicotomía del bien y del mal sin discernimiento crítico.

Por el contrario, la trayectoria de Woyzeck es una transformación a la inversa. De lo divino pasa a lo diabólico, a la locura, al asesinato, dejando en poder de Andrés esa cruz (escena 20), símbolo macabro de la muerte de Dios, la muerte de la Palabra. Entonces se arroja al otro extremo: «María, tú eres hermosa como el pecado. ¿cómo puede ser tan hermoso el pecado mortal?» (escena 10). Él tampoco puede resolver esa contradicción y entonces se le aparecen los fantasmas en la imaginación y en el sueño, su fantasía está desasistida de la razón (pues no la puede encontrar en ninguna parte). Su locura es irreversible o como dice Goya: El sueño de la razón produce monstruos, Caprichos, $\mathrm{n}^{\circ}$ 43. Si Woyzeck pudiera burlarse o perorar sentencias como el operario $l^{\circ}$ (escena 12) se salvaría. Pero él lleva muy dentro el sentido trágico de la vida grotesca. A diferencia de los títeres que le rodean y empujan, él se toma en serio la virtud, ignora que no existe tal cosa, y ni siquiera sabe escuchar la sentencia de Andrés, muy lúcida, muy shakesperiana: «Tú, discordia ¿por el ser humano?»(escena 11). La última creencia después del crimen que le queda a Woyzeck es 
la visión de lo diabólico manifestado en todo: «La vida es así. El diablo se lleva a unos y deja a otros [...] ¿ soy yo un asesino? ¿Qué miráis? ¡Contemplaos a vosotros mismos!» (escena 23). Es el gesto trágico del héroe que comprende el error al que ha sido arrastrado por los demás y por su destino.

Cuando Woyzeck no ve otra salida que el crimen está ciego, su razón ya no es razón, es instinto ciego y brutal. Es la misma bestia de la que hablaba el puestero de la quinta escena. Pero ¿acaso asiste la razón a alguno de los que circundan a Woyzeck? La desigualdad, la virtud, la justicia, ¿no se contradicen?, ¿no son antirracionales?, o como dice María una escena antes: «Si están locos de razón, entonces una misma está loca» (escena 4).

Con esta parodia de la razón, Büchner tal vez se estaba limpiando la chaqueta casposa de la Razón dieciochesca porque ésta no podía sobrevivir en un mundo aburguesado de normas por un lado y en guerra declarada contra el romanticismo, por otro. Mozart también debió pensar algo similar cuando no supo qué hacer con el moro Monóstatos, si condenarlo o simplemente separarlo como el guisante agusanado de Grillparzer. Lo que «debería ser» no existe en la realidad. En las alusiones a la religión, ¿no hay acaso una falta de fe? ¿No es una parodia de la palabra de Dios para desenmascarar las contradicciones y la opresión sociales?

Pocas obras se han escrito con esta virulencia que se arrastra a sí misma como en Woyzeck. Pero toda ella responde a una medida, a una nueva óptica artística que iguala desmesura y realidad; la realidad supera a la ficción con creces. En la primera escena está encerrado el tema principal de la obra; cumple la función de una obertura en la que se contiene ya la resolución final. Así hay que interpretar la visión apocalíptica del personaje central: «Un fuego recorre el cielo y se oye un atronador ruido de trompetas» (escena 1). La descripción es puramente pictórica y se hacen continuas alusiones a la luz: el sol, el calor, el cielo gris, el crepúsculo (alba), la noche... Sobre todo hay que destacar el carácter marcado de dos colores: el rojo y el negro, la sangre y la muerte, el crepúsculo y la noche. Y hay que destacarlos no sólo porque aparecen en la escena sino porque revelan los impulsos interiores de los personajes. La fuerza expresiva está en íntima relación con el color y la luz.

Los diálogos son cortos, como en staccato, y anuncian también estados anímicos profundos, subjetivos. Los personajes no se entienden, están incomunicados, hablan casi idiomas diferentes. Parecen diálogos de locos. Cada personaje está pendiente de su historia personal. Aquí Büchner es también deudor del genio de Shakespeare. En ciertos momentos Woyzeck actúa como Hamlet, envuelto en una locura que es el reflejo de la locura del mundo, y hablando un lenguaje secreto: «[...] Tenemos un cielo tan bonito, firme y gris. Le dan ganas a uno de echarle una polea y colgarse de ella, solo por pensar entre el sí y el no. Mi capitán, ¿sí y no? ¿Es el no culpable del sí o el sí del no?» (escena 9). Lenguaje que deja tan estupefacto al capitán como Hamlet a Polonio o al rey, y sin embargo está bien claro que es una parodia de ellos mismos. Los seres humanos están totalmente alejados unos de otros, y dentro de cada uno de ellos está el vacío: «Cada persona es un abismo. Uno se marea cuando mira en él» (escena 10) Esta visión del ser humano nos ha de parecer moderna en los personajes de Beckett por ejemplo, pero también está presente en Shakespeare o en Quevedo.

El tema del cuchillo y la sangre recuerda muy de cerca a la sangre que vuelve loca a la terrible lady Macbeth. Como ella, Woyzeck se siente manchado de sangre por todas partes y no hay agua suficiente para borrarlas. Y también la locura de lady Macbeth es la de Woyzeck cuando exclama enajenado: «María, ¿qué cuerda roja tienes en el cuello?» Esta expresión es quizá la más intensa de toda la obra. También en relación con las semejanzas shakesperianas hay que señalar la función del sueño. Como Macbeth, Woyzeck no puede conciliar el sueño, y le hablan las paredes mirándole «con ojos de cuchillo». O los papeles del loco y de los operarios $1^{\circ}$ y $2^{\circ}$ que recuerdan a tantos personajes de Shakespeare, en especial a los de La Tempestad. Tenía razón Goethe cuando hablaba del peligroso vigor que llega a hundir a los jóvenes talentos pues sólo les conduce a la emulación. Para él «sólo había que leer una tragedia de Sha-

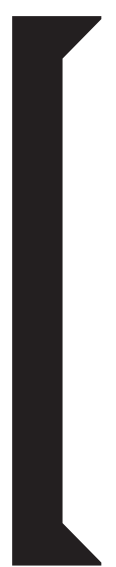

El tema del cuchillo y la sangre recuerda

muy de cerca a la sangre que vuelve loca a la terrible lady Macbeth.

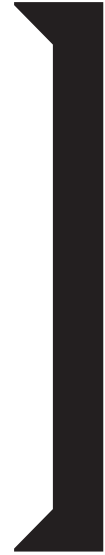

kespeare al año». En esta relación de semejanzas y afinidades ha de reconocerse sin embargo al genio que habita en la recreación, no en la copia. Esta actitud de los personajes que anuncia otras posibilidades expresivas, se adelanta a la que quizá sea el más revolucionario (en la forma) de todos los capítulosde Madame Bovary, «Los comicios».

Hay una fuerza expresiva muy poderosa, fuerza en imagen, en parodia, en caricatura y en disparate. Es un ritmo ditirámbico, casi orgiástico a golpe de tambor, y sin embargo hay una agrupación de todos estos elementos en la unidad fundamental de la obra: la tragedia.

En la lectura uno tiene la sensación de presentir la aparición inmediata en la escena de personas que fueran monos o asnos y de monos que fueran seres humanos; de ver bocas hambrientas en rostros sin ojos, de ver personas con cuerpo de gallina, de ver violentas lenguas sobre la piel... ;A tal extremo están llevados la animalidad, la bestialidad, los sueños, los deseos!

El doctor ruge, al suboficial se le cae la baba cuando ve a María: «iQué hembra!» (escena 5) Woyzeck pierde una pelea: es la pelea de los ciervos que se asestan golpes en la cornamenta cuando están en celo. Tales cosas ocurren en la re-

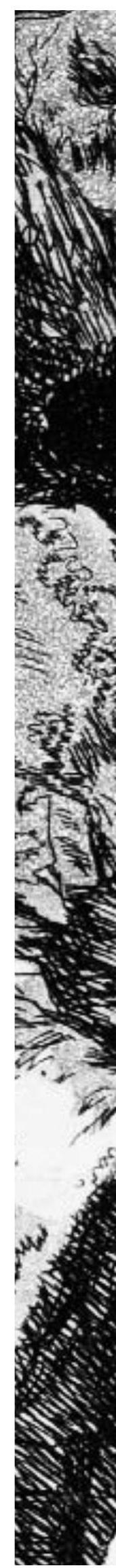




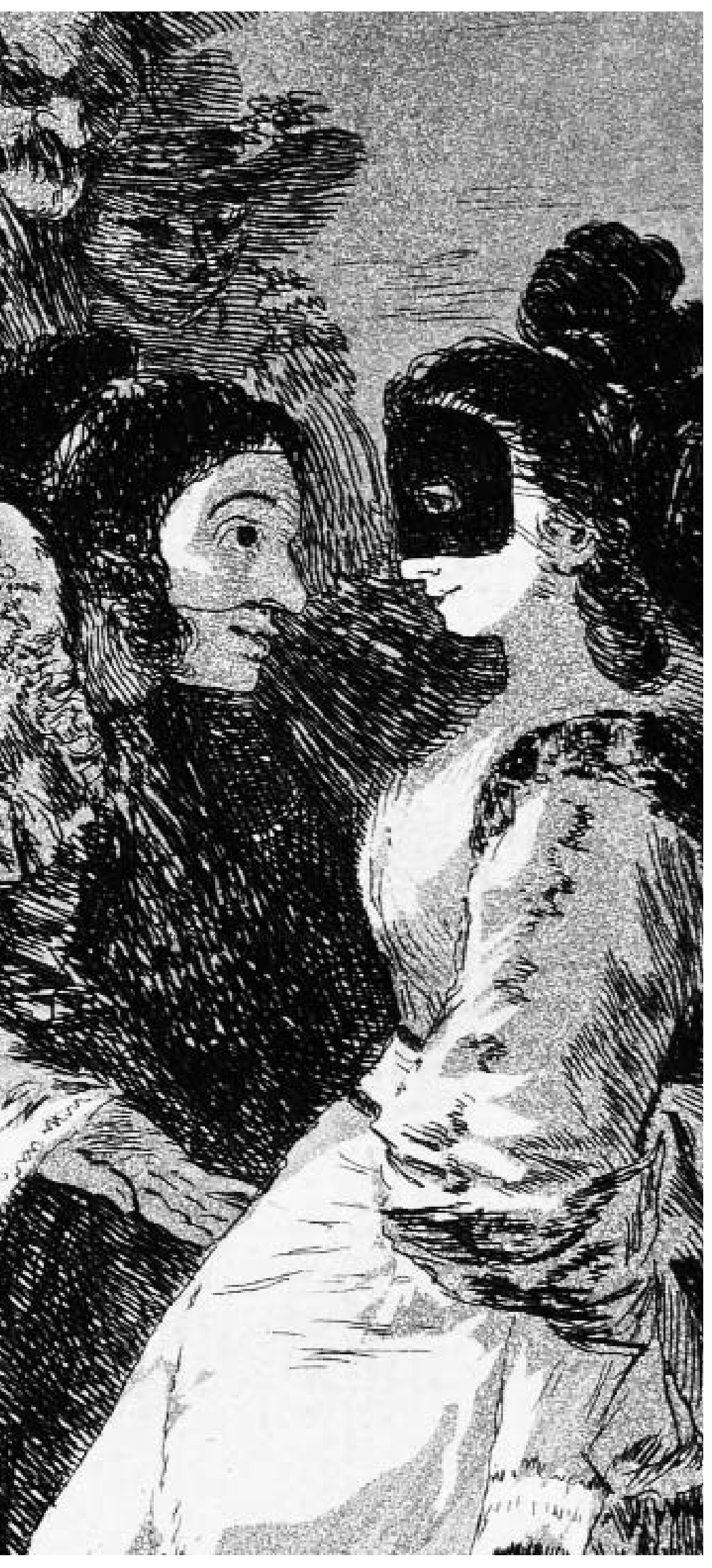

alidad, y Büchner las convierte en método dramático, en fuerza expresiva. Al presentar al ser humano como animal no se recurre a la fábula y la moraleja como la entendieron los dieciochescos, sino que se está procediendo a la deformación intencionada; algo así como un juego para descubrir la verdad por la apariencia, técnica expresiva ésta que ha sido muy utilizada, sobre todo en el cine. Basta citar dos títulos de películas: Padre patrón y Escenas de caza en Baviera, en la última de las cuales incluso se puede seguir el mismo tema que en Woyzeck. También hay un intento de ridiculización al acudir a este método, pero sobre todo lo que quiere destacarse de esta manera es la realidad.

Del carácter y de la actitud artística que emprende Büchner, tal vez el ejemplo más claro esté en el niño de la escena 21 que al oír la canción de la muchacha replica: «Esto no es bonito». No le parece bella la imagen ideal, bucólica del poema de la chica, prefiere la realidad. En vez de pífanos y violines y prados y soles y medias de seda roja debería ser el sonido del ta-

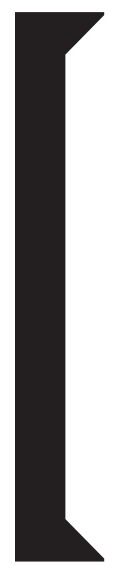

Al presentar al ser humano como animal

no se recurre a la fábula y la moraleja

como la entendieron los dieciochescos,

sino que se está procediendo a la deformación

intencionada; algo así como un juego

para descubrir la verdad por la apariencia.

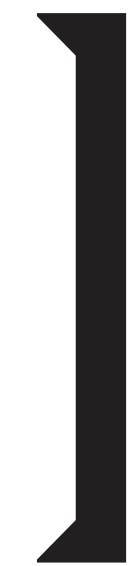

jo de un cuchillo en la blanda carne o el sonido de las cabezas decapitadas cayendo en un cubo de hojalata. Por eso es imposible otro cuento que el de la abuela: «Todo estaba muerto».

En todo momento se presienten escenas macabras mientras que la miseria espiritual y física (material) le impiden a Büchner otra expresión que no sea la caricatura. Sus hallazgos son las posibilidades escénicas que inaugura a inicios del siglo XIX, mucho antes que el expresionismo, y la configuración de una actitud lacerante que ha sido legada a nuestro siglo, necesitado de caricaturistas que pongan el dedo en la llaga de la infamia, de la injusticia y de la estupidez voluntarias. No hay nadie mejor que Goya para la justa intelección de esta actitud en cualquier época de crisis y de aplastamiento de los valores de la razón romántica.

BIBLIOGRAFÍA

Büchner, Georg (1980), Werke und Briefe. Múnich: Carl Hanser Verlag, Los Caprichos of Francisco de Goya (1969). Nueva York : Dover Publications Inc. 